\title{
Comparison of Thermal and Flow-Based Modulation in Comprehensive Two-Dimensional Gas Chromatography-Time-of-Flight Mass Spectrometry (GC $\times$ GC-TOFMS) for the Analysis of Base Oils
}

\author{
Haleigh A. Boswell ${ }^{1}$, Matthew Edwards ${ }^{1,2}$ and Tadeusz Górecki 1,*(D) \\ 1 Department of Chemistry, University of Waterloo, 200 University Avenue West, Waterloo, \\ ON N2L 3G1, Canada; haleighboswell@chevron.com (H.A.B.); medwards@sepsolve.com (M.E.) \\ 2 SepSolve Analytical Ltd., 826 King St N, Unit 15, Waterloo, ON N2J 4G8, Canada \\ * Correspondence: tgorecki@uwaterloo.ca
}

Received: 29 October 2020; Accepted: 26 November 2020; Published: 4 December 2020

check for updates

\begin{abstract}
Base oils are produced by refining crude oil or through chemical synthesis. They are a key component of engine oils. With an immense range of carbon numbers and boiling points, analyzing such complex mixtures is very difficult. The need to monitor industrial petroleum processing steps, as well as to identify petrochemical environmental pollutants, drives the search for improved characterization methods. Comprehensive two-dimensional gas chromatography $(\mathrm{GC} \times \mathrm{GC})$ is one of the best tools for that. The modulator used in GC $\times$ GC is responsible for trapping/sampling the first dimension $\left({ }^{1} \mathrm{D}\right)$ column analytes, then reinjecting them in the form of narrow bands onto the second dimension $\left({ }^{2} \mathrm{D}\right)$ column for further separation. Modulators used today generally fall into two categories, thermal and flow ones. Heater-based thermal modulators trap the ${ }^{1} \mathrm{D}$ column effluent at or above ambient temperatures. Flow-based modulators utilize storage loop(s) to collect the ${ }^{1} \mathrm{D}$ effluent, which is subsequently flushed into the second-dimension column for further separation. A single-stage, consumable-free thermal modulator and a reverse fill/flush flow modulator were compared for the characterization of base oils. Both were evaluated on their ability to achieve separation of several conventional and synthetic engine oils components. A reverse column set, polar ${ }^{1} \mathrm{D}$ and nonpolar ${ }^{2} \mathrm{D}$, allowed group-type analysis of all classes, including linear, branched, and aromatic species. The results show the ability to achieve a comprehensive separation of specific compound classes and the differentiation of engine oil types and manufacturers. Soft ionization assisted in tentative identification of two alkylated diphenylamines in each sample. The advantages and limitations of both thermal and flow modulation are presented.
\end{abstract}

Keywords: comprehensive two-dimensional gas chromatography (GC $\times \mathrm{GC})$; thermal modulator; reverse fill/flush flow modulator; base oils; group analysis; resolution; additives; antioxidants

\section{Introduction}

As a major component of lubricating greases, engine oils and metal processing fluids, base oils are encountered in both industry and in everyday life. They are produced by refining crude oil using typical processes of distillation, cracking, hydrogenation, and dewaxing [1,2], or by chemical synthesis. Originating from heavy crude oils, the hydrocarbons in base oils range between 18 and 40 carbon atoms with a boiling point range between $288^{\circ} \mathrm{C}$ and $566^{\circ} \mathrm{C}$ [1]. To differentiate the levels of refinement, the American Petroleum Institute (API) classifies these oils into five groups. Group 1 contains the least refined, conventional petroleum base oils. Group 2 has a better grade of petroleum when compared to group 1, partially produced by hydrocracking. Group 3 contains the best grade of petroleum that 
is fully produced by hydrocracking. The synthetic oils and poly-alpha-olefins (PAOs) are placed in group 4. Finally, any other types that were not previously mentioned are placed in group 5 .

Engine oils' main functions include lubrication of the moving parts, cleaning, inhibiting corrosion, and helping cool the engine by removing heat from the moving parts [3]. These oils can be differentiated by their base stock and viscosities, which define their working capability. Base stocks are separated into three groups: Synthetic, semi-synthetic, and mineral [4]. The Society of Automotive Engineers (SAE) defines two kinematic viscosities for engine oils: one at a low and one at a high temperature. The value that is directly followed by a "W" refers to the winter, or low-temperature kinematic viscosity value (SAE 0W, 5W, 10W, and 20W) [4]. The values that do not contain a letter refer to the high-temperature kinematic viscosity value (SAE 20, 30, 40, and 50) [4].

Continual testing throughout the production process is vital to ensure the oils are performing to their necessary regulations and requirements. When analyzed by conventional one-dimensional gas chromatography (1D-GC), a large raised baseline region due to unresolved complex mixture (UCM) is observed, making it difficult to separate co-eluting compounds and differentiate the complex nature of the oil matrix [5]. This shortcoming of 1D-GC drives the search for more capable methods. Comprehensive two-dimensional gas chromatography $(\mathrm{GC} \times \mathrm{GC})$ has become an established method for the analysis of complex mixtures since its inception in the 1990s. In fact, one of the first GC $\times$ GC applications was the investigation of petroleum [6]. By implementing two separate stationary phases, the sample in GC $\times$ GC is subjected to an orthogonal separation according to both polarity and volatility. A so-called 'roof tile effect' is a common visual characteristic of GC $\times$ GC chromatograms of petroleum fractions that allows differentiation of various chemical classes in which compounds from similar homologous groups are arranged together in sequential order by their carbon number [7]. This effect is extremely useful when performing a group-type separation, specifically PIONA (Paraffins, Isoparaffins, Olefins, Naphthenes, and Aromatics) [6]. Owing to enhanced resolution when compared to 1D-GC, GC $\times$ GC allows an in-depth investigation of trace components, such as biomarkers and chemical additives, within petrochemical samples.

Chemical additives and antioxidants are typically added to an oil or lubricant to enhance its performance, alleviate adverse properties, and prevent oxidation $[8,9]$. Antioxidants are added to eliminate or slow down the oxidation processes to which hydrocarbons are prone at high temperatures [9]. The two main classes of antioxidants are alkylated diphenylamines and sterically hindered phenolic compounds [9]. GC $\times$ GC aids in separating and identifying these compounds that may be at trace levels, hidden within the UCM in a 1D-GC chromatogram. Identification of these compounds is vital in distinguishing brands, blends, and kinematic viscosities (low vs. high temperature) of oils.

The so-called "normal" GC $\times$ GC column configuration includes a nonpolar column in the first dimension and a semi-polar/polar column in the second dimension. However, this is not an advantageous configuration in regard to the hydrocarbons found within engine oils. By employing a polar column in the first dimension $\left({ }^{1} \mathrm{D}\right)$ and a nonpolar column in the second dimension $\left({ }^{2} \mathrm{D}\right)$, a reverse column setup takes advantage of the operating mechanism of GC $\times$ GC to give an enhanced separation of samples with compositions similar to those of engine oils [10-14]. The reverse column configuration specifically aids in group-type analysis by increasing the resolution of the straight chain and branched alkanes from the aromatic hydrocarbons [15]. In a comparison of both column configurations, Tran et al. found that the normal setup used the two-dimensional space poorly, while the reverse setup improved the separation of the nonpolar compounds [16].

To ensure the sample is properly transferred from the ${ }^{1} \mathrm{D}$ column to the head of the ${ }^{2} \mathrm{D}$ column, a modulator must be employed. As the 'heart' of a GC $\times$ GC system, the modulator must collect or sample the components of the ${ }^{1} \mathrm{D}$ column effluent and create a narrow band to be injected into the ${ }^{2} \mathrm{D}$ column while preserving the previous separation achieved in the ${ }^{1} \mathrm{D}$ column. To accomplish the latter objective, the modulator must sample each ${ }^{1} \mathrm{D}$ peak at least three to four times [17]. The commercially available modulators can be separated into two classes: thermal modulators and flow modulators. 
Detailed information on the principles of GC $\times$ GC and the various modulator designs is beyond the scope of this paper. Interested readers are referred to one of many excellent review articles, e.g., [18-23]. In addition, several publications have previously compared cryogenic and flow modulators in the analysis of petroleum products $[24,25]$.

Mass spectrometry is commonly employed to assist in identifying analyte peaks. Time-of-flight mass spectrometry (TOF-MS) is the method of choice for GC $\times$ GC owing to its fast acquisition speed and full-scan-range capabilities. Standard electron ionization (EI) employs an energy of $70 \mathrm{eV}$. As most molecules have significantly lower ionization energies, the mass spectra contain an abundance of small fragment ions, often leaving the molecular ion barely visible or absent [26]. Soft ionization utilizes a lower energy to ionize the compound, resulting in less fragmentation [26]. The spectra typically contain a molecular ion in greater abundance and fewer, but more distinctive fragmentation ions. Some limitations of common soft ionization techniques include a different ion-source configuration with a reagent gas, weak ion currents, and limited sample applicability. The variable-ionization-energy TOF-MS used in this study (Select-eV) addresses these issues by performing both hard and soft ionization ranging between 70 and $10 \mathrm{eV}$ on a single instrument, without the need for reagent gases, pressure adjustments, or alterations to the ion source [26,27]. The Select-eV ion optics allow for a high potential difference to be used to accelerate the electrons away from the filament. Their energy is then reduced before they arrive in the ion chamber, resulting in no loss of sensitivity. Owing to the unique design of the ion source, there is no clustering of electrons around the filament. This results in reduced spectral noise, reduced fragmentation, enhanced selectivity, and an increase in intensity of the molecular ion. The identification of specific isomers within motor oil samples was successfully accomplished by utilizing the low- and high-ionization-energy mass spectra in combination with the separation power and resolution of GC $\times$ GC [26].

The goal of this study was to compare a single-stage, consumable-free thermal modulator and a commercially available reverse fill/flush differential flow modulator on their separation capabilities of various engine oils. The oils differed with regard to their blend, viscosities, and brand. The modulator platforms were evaluated in terms of their ability to provide group-type separation, resolution from the UCM, and identification of additives through soft ionization. Similarities and differences between the samples were also investigated.

\section{Materials and Methods}

\subsection{Base Oil Samples}

A total of 8 different motor oils were acquired from a local Canadian Tire retail company differing in brand, viscosity (two different cold- and high-temperature performance values), and blend. SAE $10 \mathrm{~W}-30$ and SAE 5W-20 were selected in both conventional and synthetic blends from Brand A and Brand B for the analyses. Each sample was diluted by adding $0.4 \mathrm{~mL}$ of oil to a $1 \mathrm{~mL}$ volumetric flask and filling to the mark with $\mathrm{CS}_{2}$ (Sigma-Aldrich, Oakville, ON, Canada). An aliquot of each sample solution was transferred to $2.0 \mathrm{~mL}$ glass GC vials with PTFE-lined silicone septa (Chromatographic Specialties, Brockville, ON, Canada) for analysis by Comprehensive Two-Dimensional Gas Chromatography_-Time-of-Flight Mass Spectrometry/Flame Ionization Detection (GC $\times$ GC-TOF-MS/FID), as described in Section 2.2.

\subsection{GC $\times$ GC Instrumentation}

Due to the operational differences between flow and thermal modulation, a direct comparison using the same parameters with both devices could not be accomplished. Therefore, both systems were used under their optimal conditions to achieve the best separation possible. Instrumental conditions, such as column dimensions and column flow rates, were different; however, other parameters, such as the oven temperature program, injection split ratio and detector settings were kept the same. Both platforms were set-up with a reverse column set utilizing the same ${ }^{1} \mathrm{D}$ and ${ }^{2} \mathrm{D}$ column stationary phases. 
The GC $\times$ GC system consisted of an Agilent 6890 gas chromatograph (Agilent Technologies, Santa Clara, CA, USA) equipped with a split/splitless injector and an on-column injector used as an auxiliary pressure source. A Bench-TOF-Select mass spectrometer (Markes International, Llantrisant, UK) and an FID detector were employed simultaneously by placing a two-way splitter (SepSolve Analytical Ltd., Peterborough, UK) at the end of the ${ }^{2} \mathrm{D}$ column. An Agilent 7683 series autoinjector was used to make $1 \mu \mathrm{L}$ injections of each sample using a 30:1 split ratio. The inlet temperature was set at $300{ }^{\circ} \mathrm{C}$ with a $4 \mathrm{~mm}$ ID precision split liner with wool (Restek Corp., Bellefonte, PA, USA). Helium (Praxair, Kitchener, ON, Canada) with a purity of $99.999 \%$ was used as the carrier gas. The oven temperature program was $40{ }^{\circ} \mathrm{C}$ to $340{ }^{\circ} \mathrm{C}$ at $5{ }^{\circ} \mathrm{C} / \mathrm{min}$ with a $15 \mathrm{~min}$ hold. The FID was operated at $300^{\circ} \mathrm{C}$ with an acquisition rate of $200 \mathrm{~Hz}$ and gas flows of $40 \mathrm{~mL} / \mathrm{min} \mathrm{H}_{2} / 450 \mathrm{~mL} / \mathrm{min}$ air (both from Praxair). The TOF-MS transfer line and ion source were kept at $250^{\circ} \mathrm{C}$. The TOF-MS acquired the spectra at a frequency of $50 \mathrm{~Hz}$ with a mass range of 50 to $600 \mathrm{~m} / \mathrm{z}$. Ionization energies of both 14 and $70 \mathrm{eV}$ were explored for the engine oil samples. ChromSpace (Markes International) was used for data acquisition and processing of the TOF-MS data. ChemStation (Agilent Technologies) and ChromSpace (Markes International) were used for data acquisition and processing of the FID data, respectively.

The thermal modulation platform consisted of the University of Waterloo single-stage, consumable-free thermal modulator [28]. The column configuration consisted of a $20 \mathrm{~m} \times 0.18 \mathrm{~mm} \times 0.18 \mu \mathrm{m}$ Mega 17-MS from MEGA (Legnano, Italy) in the first dimension, and a $70 \mathrm{~cm} \times 0.15 \mathrm{~mm} \times 0.15 \mu \mathrm{m}$ Rxi-1MS from Restek (Bellefonte, PA, USA) in the second dimension. A $5.0 \mathrm{~cm} \times 50 \mu \mathrm{m}$ deactivated restrictor column from Molex (Lisle, Illinois, USA) was placed after the ${ }^{1} \mathrm{D}$ dimension column as a pressure restriction before the trapping capillary of the modulator. The trapping capillary contained a proprietary stationary phase. It was placed within the cooling pads of the modulator. The ${ }^{1} \mathrm{D}$ column length entered into the software was $30.8 \mathrm{~m} \times 0.15 \mathrm{~mm} \times 0.15 \mu \mathrm{m}$ to account for the pneumatic resistance of the entire column train from ${ }^{1} \mathrm{D}$ to ${ }^{2} \mathrm{D}$. An Agilent two-way purged splitter was placed after the second-dimension column in order to split the column effluent between the FID and the TOF-MS detectors. An Agilent splitter calculator was used to determine the necessary transfer line dimensions with a flow ratio of 1:1 between detector 1 (FID) and detector 2 (TOF-MS). A $1.64 \mathrm{~m} \times 0.15 \mathrm{~mm}$ transfer line was connected to the FID, and a $2.19 \mathrm{~m} \times 0.15 \mathrm{~mm}$ transfer line was connected to the TOF-MS. A total length of $3.83 \mathrm{~m} \times 0.15 \mathrm{~mm}$ was programmed into the software as the second-dimension column in order to employ a makeup flow of $4.4 \mathrm{~mL} / \mathrm{min}$ from the back inlet (auxiliary pressure control). A flow of $2.0 \mathrm{~mL} / \mathrm{min}$ was used in ${ }^{1} \mathrm{D}$, and a flow of $3.0 \mathrm{~mL} / \mathrm{min}$ (each) was delivered to the FID and the TOF-MS after auxiliary flow was added. This achieved holdup times of 0.014 and $0.016 \mathrm{~min}$ for the FID and TOF-MS, respectively. A modulation period of $8 \mathrm{~s}$ was used. All connections on the Agilent splitter were made with the Agilent Ultimetal Plus Flexible Metal Ferrules from Agilent Technologies (Mississauga, ON, Canada). Connections between the ${ }^{1} \mathrm{D}$ column and the restrictor, and subsequently the restrictor and the trapping capillary, were made with a Siltite Double Taper Ferrule/Micro-union and Siltite Mini Ferrule (Trajan, Victoria, Australia), respectively.

The flow modulation platform consisted of the INSIGHT Reverse Fill/Flush Flow Modulator from SepSolve Analytical Ltd. (Peterborough, UK) [29]. The column configuration consisted of a $20.0 \mathrm{~m} \times 0.18 \mathrm{~mm} \times 0.18 \mu \mathrm{m}$ Mega 17MS from MEGA (Legnano, Italy) in the first dimension and a $9.1 \mathrm{~m} \times 0.25 \mathrm{~mm} \times 0.25 \mu \mathrm{m}$ Rxi-1 from Restek (Bellefonte, PA, USA) in the second dimension. A $10.0 \mathrm{~m} \times 100 \mu \mathrm{m}$ of deactivated silica tubing (Trajan Scientific, Melbourne, Australia) was used as the bleed line. A two-way-nonpurged splitter from SepSolve Analytical Ltd. (Peterborough, UK) was used to divide the ${ }^{2} \mathrm{D}$ column effluent between the FID and the TOF-MS. With a constant flow of $0.5 \mathrm{~mL} / \mathrm{min}$ in ${ }^{1} \mathrm{D}$ and a constant flow of $21.3 \mathrm{~mL} / \mathrm{min}$ in ${ }^{2} \mathrm{D}$, the SepSolve flow calculator assisted in determining the necessary auxiliary pressure to apply in order to achieve the correct flow through the bleed line, as well as the proper transfer line dimensions for both the FID and TOF-MS. An auxiliary pressure of $45 \mathrm{psig}$ was needed to achieve a flow of $0.5 \mathrm{~mL} / \mathrm{min}$ within the bleed line to match the flow in the first dimension at the starting oven temperature. Transfer lines of deactivated fused silica tubing 
with dimensions of $0.8 \mathrm{~m} \times 0.32 \mathrm{~mm}$ and $1.0 \mathrm{~m} \times 0.18 \mathrm{~mm}$ (SGE Analytical, Ringwood, Australia) were employed for the FID and the TOF-MS, respectively. These dimensions gave identical holdup times of $0.0039 \mathrm{~min}$ for both the FID and the TOF-MS. The two-way splitter employed a 4:1 split between the FID and TOF-MS with flows of 16.56 and $4.78 \mathrm{~mL} / \mathrm{min}$, respectively. All connections to the necessary ports were made with SilFlow Ferrules from Trajan (Victoria, Australia). A modulation period of $4 \mathrm{~s}$ with a $100 \mathrm{~ms}$ flush was used.

\subsection{Thermal Modulation}

The single-stage, consumable-free thermal modulator shown in Figure 1 was described elsewhere [28]. For the analysis of base oils, only passive cooling was used due to the high boiling points of the analytes. In both designs, the trapping capillary temperature would lag behind the oven temperature during the run, assisting in the analysis of semi-volatiles.

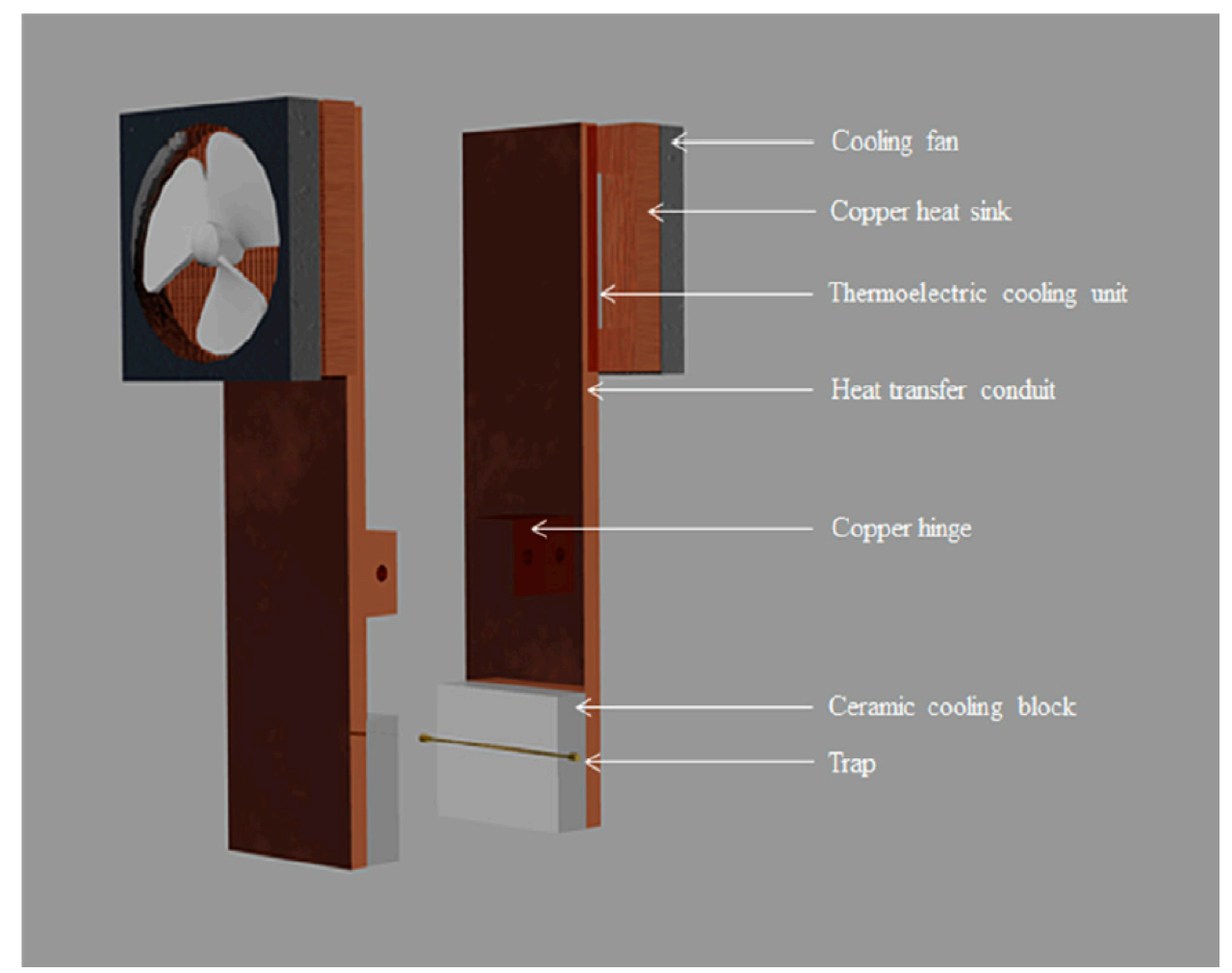

Figure 1. Design of the single-stage, consumable-free thermal modulator from the University of Waterloo [28]. Reprinted from Journal of Chromatography A, 1391, 93-101, Copyright (2016), with permission from Elsevier.

\subsection{Flow Modulation}

As seen in Figure 2, the INSIGHT reverse fill/flush flow modulator consisted of a single microchannel plate with 7 ports and a complementary two-way non-purged splitter with 3 ports for coupling to the mass spectrometer and a single-channel detector [29]. 
(a)

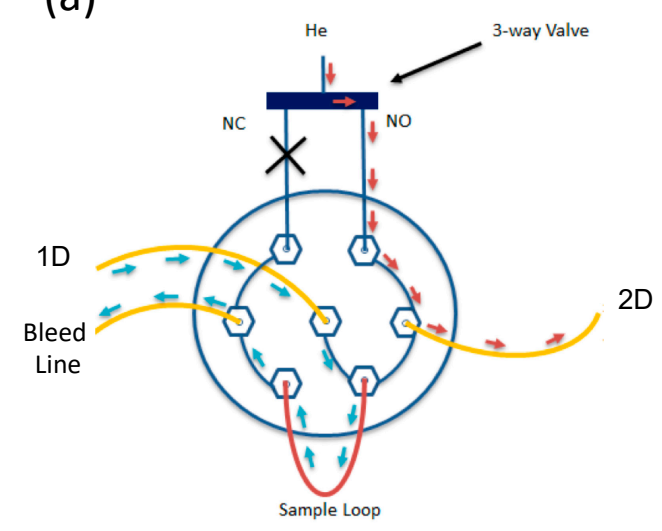

Fill

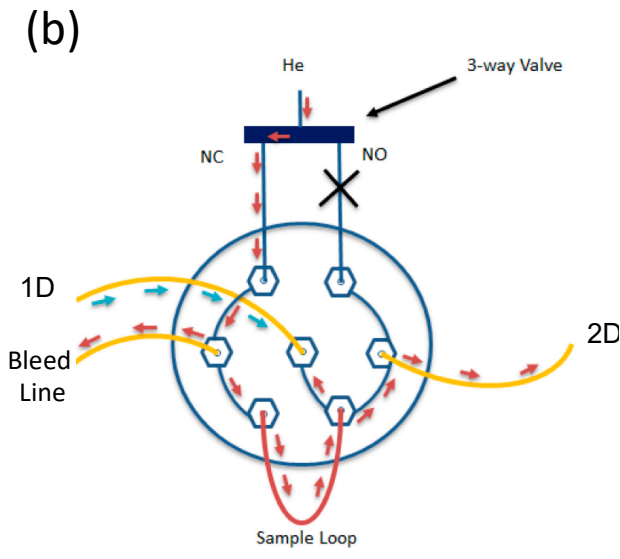

Flush

Figure 2. (a) Flow path of the fill stage of the Insight RFF flow modulator, and (b) flow path of the flush stage of the Insight RFF flow modulator [29].

\section{Results and Discussion}

\subsection{Ion Source Tailing}

As previously mentioned, the ${ }^{2} \mathrm{D}$ column effluent was split for dual detection to the FID and TOF-MS for both modulator platforms. However, the thermal platform required an additional auxiliary flow via a purged two-way splitter to reduce the ion source tailing. When comparing the split flow ratios for both platforms, the proportion of the sample directed toward the TOF-MS varied significantly. For the flow modulator, the ${ }^{2} \mathrm{D}$ effluent was split 1:4, with about $4 \mathrm{~mL} / \mathrm{min}$ directed to the MS and the remaining $16 \mathrm{~mL} / \mathrm{min}$ directed to the FID. For the thermal modulator with the auxiliary flow, the ${ }^{2} \mathrm{D}$ effluent was split 1:1, with $3 \mathrm{~mL} / \mathrm{min}$ directed to the $\mathrm{MS}$ and $3 \mathrm{~mL} / \mathrm{min}$ directed to the FID. Due to the different operational principle of each platform, it was not possible to achieve the exact same flow to both detectors. The analytes introduced into the ion source after flow modulation had significantly higher concentrations, resulting in pronounced tailing. This was strictly an issue with the ion source of the TOF-MS, not the thermal modulator platform itself, as the FID trace showed no ${ }^{2} \mathrm{D}$ tailing. The closed design of the Benchtop Select-eV ion source made it difficult for the higher-molecular-weight compounds to diffuse out of the source in a timely fashion, ultimately creating tailing. As seen in Figure $3 \mathrm{a}, \mathrm{c}$, the unprocessed linear chromatogram displayed a large baseline rise for the TOF-MS trace, while the FID trace returned completely to baseline (Figure 3b,d).

Figure $4 \mathrm{a}, \mathrm{c}$ show zoomed-in chromatograms illustrating the tailing observed with the TOF-MS, while the FID trace again shows Gaussian peaks that return to baseline (Figure $4 b, d$ ).

The ion source tailing is extremely prominent in the unprocessed two-dimensional chromatograms, as seen in Figure 5a,c. The heavy compounds within the UCM showed as a broad band across the entire two-dimensional space after data processing, making it almost impossible to detect any trace analytes. Baseline correction and data processing were required in order to achieve a two-dimensional chromatogram with distinguishable peaks. Unprocessed two-dimensional chromatograms acquired with the FID showed no tailing, with a clear distinction of groups surrounding the UCM (Figure 5b,d). Overall, the combination of the closed source design, heavy sample matrix, and lower flow entering the ion source led to substandard peak shapes. This was remedied by data processing built into the ChromSpace software. All TOF-MS chromatograms presented herein for both platforms were processed in this way to distinguish trace analytes. 


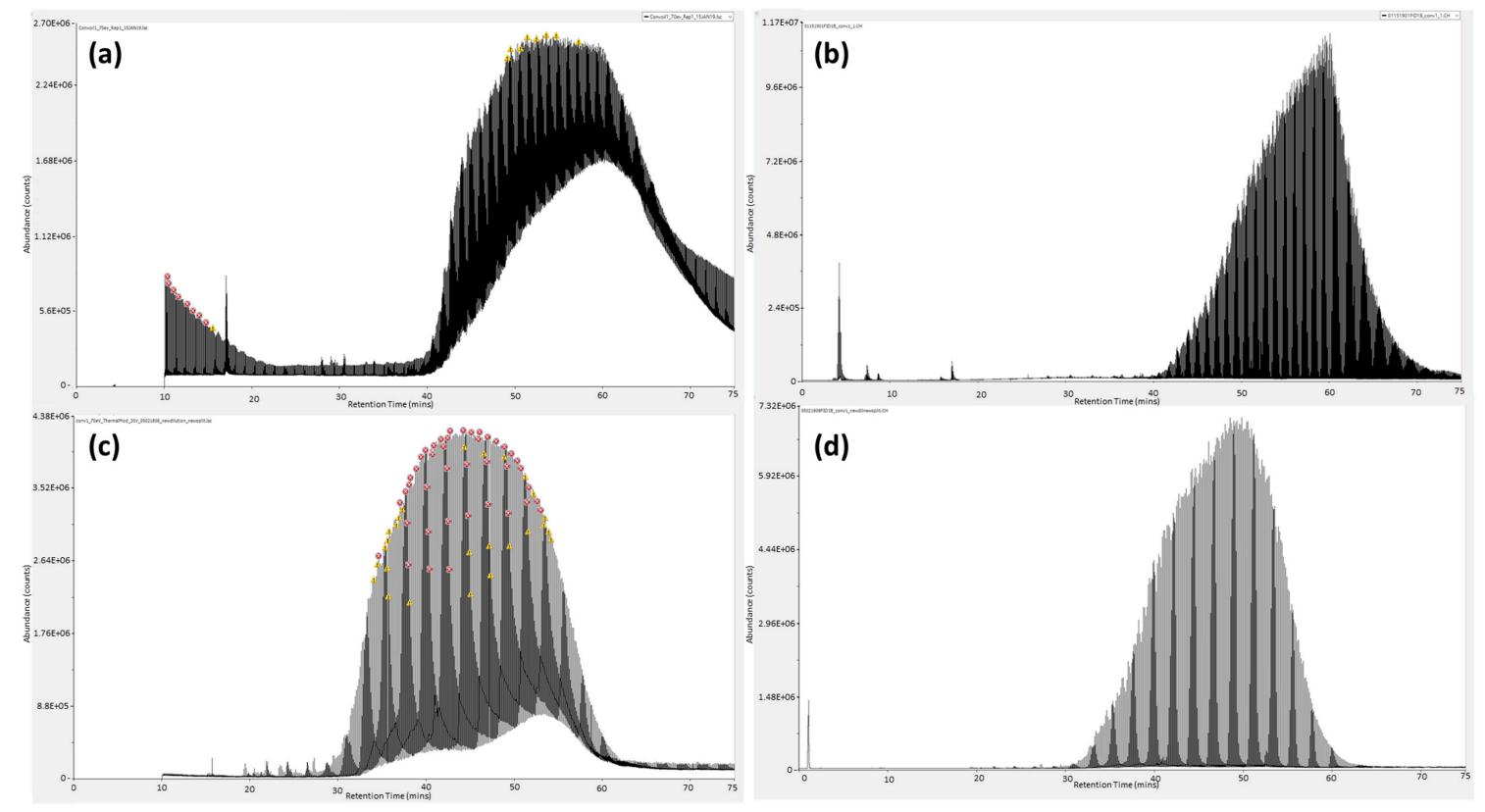

Figure 3. Unprocessed, raw signals of (a) TOF-MS trace for the flow-based platform; (b) FID trace for the flow-based platform; (c) TOF-MS trace for the thermal-based platform; and (d) FID trace for the thermal-based platform.

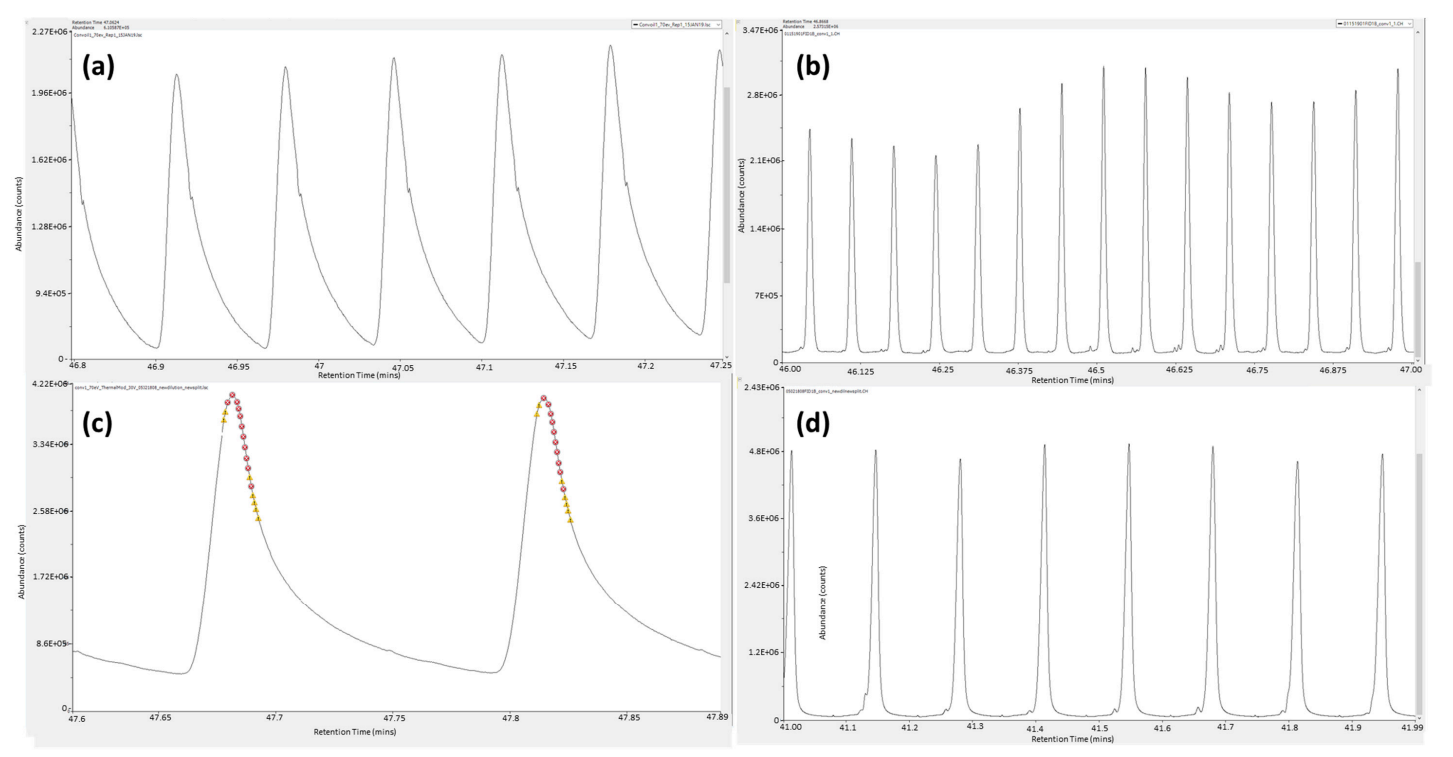

Figure 4. Unprocessed, magnified raw signals of (a) TOF-MS trace for the flow-based platform; (b) FID trace for the flow-based platform; (c) TOF-MS trace for the thermal-based platform; and (d) FID trace for the thermal-based platform.

\subsection{Group-Type Identification}

Group-type identification of hydrocarbons is a vital tool for petrochemical samples due to the complexity of the sample matrix and numerous compounds present. Instead of identifying each individual compound, group classifications based on placement within the chromatographic region and mass spectral properties can be used [30]. Each group contains specific compounds that provide a chemical characteristic and impart specific properties to the petroleum-based sample [30]. This type of separation and identification makes it possible to obtain a more complete picture of the chemical makeup, while saving time and providing an easier data processing workflow. With the ${ }^{2} \mathrm{D}$ column 
used, aromatic hydrocarbons eluted at shorter ${ }^{2} \mathrm{D}$ retention times, followed by branched alkanes and subsequently straight-chain alkanes with the latest eluting band located at a longer ${ }^{2} \mathrm{D}$ retention time [15]. Due to the use of a nonpolar column in ${ }^{2} \mathrm{D}$, the elution range of these compounds was 'stretched', allowing better differentiation between the various alkane series [16]. Alongside the preliminary estimation of the location of the various groups, summed extracted ion chromatograms of characteristic ions and fragments were used to help in the identification, as seen in Table 1 [31,32].
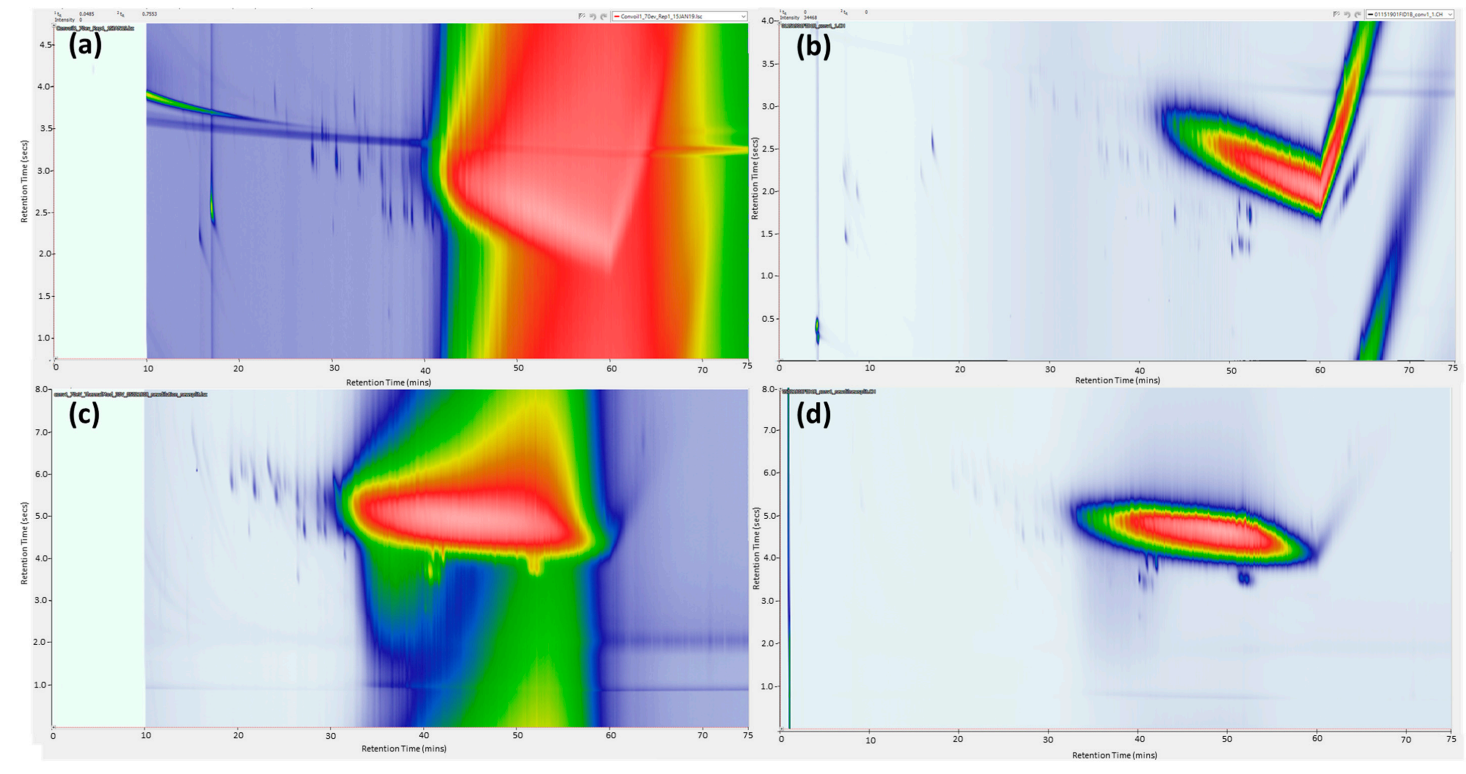

Figure 5. Unprocessed contour plots of (a) TOF-MS trace for the flow-based platform; (b) FID trace for the flow-based platform; (c) TOF-MS trace for the thermal-based platform; and (d) FID trace for the thermal-based platform.

Table 1. Different compound groups and their corresponding mass fragments [31,32].

\begin{tabular}{ll}
\hline Class & Mass Fragments \\
\hline Paraffins and isoparaffins & $43+57+71+85+99+113+127+141+155+169$ \\
Alkylbenzenes & $91+92+106+119+120+133+134+147+148+161+162+175+176$ \\
Mononaphthenes & $67+67+83+97+111+125+139+153+167$ \\
Dinaphthenes & $81+95+109+123+137+151+165+179+193$ \\
Trinaphthenes & $67+79+93+107+121+135+149+163+177+191+205+219+233+247$ \\
Naphthalenes & $141+142+155+156+169+170+183+184+197+198+211+212+225+226+239+240$ \\
\hline
\end{tabular}

The stencil feature within the ChromSpace software allows the user to manually draw around a specific region within the chromatogram, save the template, and apply it to further samples. The saved stencil is applied to the same chromatographic region based on the retention areas $\left({ }^{1} \mathrm{D}\right.$ and $\left.{ }^{2} \mathrm{D}\right)$ that are chosen by the user. Once the summed extracted ion chromatograms are completed for each group, a stencil is drawn and saved to a specific color. This is repeated for each individual group with varying colors for easy visualization. In this work, the following colors were used: Blue for paraffins and isoparaffins, green for alkylbenzenes, orange for mononaphthenes, yellow for dinaphthenes, red for trinaphthenes, and purple for naphthalenes. To ensure that the stencils were correctly identifying the specific groups, summed extracted ion chromatograms were applied to confirm the stencil location. As seen in Figure 6, the overall location of the groups was relatively similar, with varying concentrations of paraffins and substituted naphthenes across all samples. It is important to note that there was no clear separation between each group, with several overlaps between them. Due to the overlap between groups, FID could not be used for group quantitation. Alternatively, the TOF-MS could be used for semi-quantitation by analyzing standards belonging to each group because the analytes have different response factors on the TOF-MS [31]. 

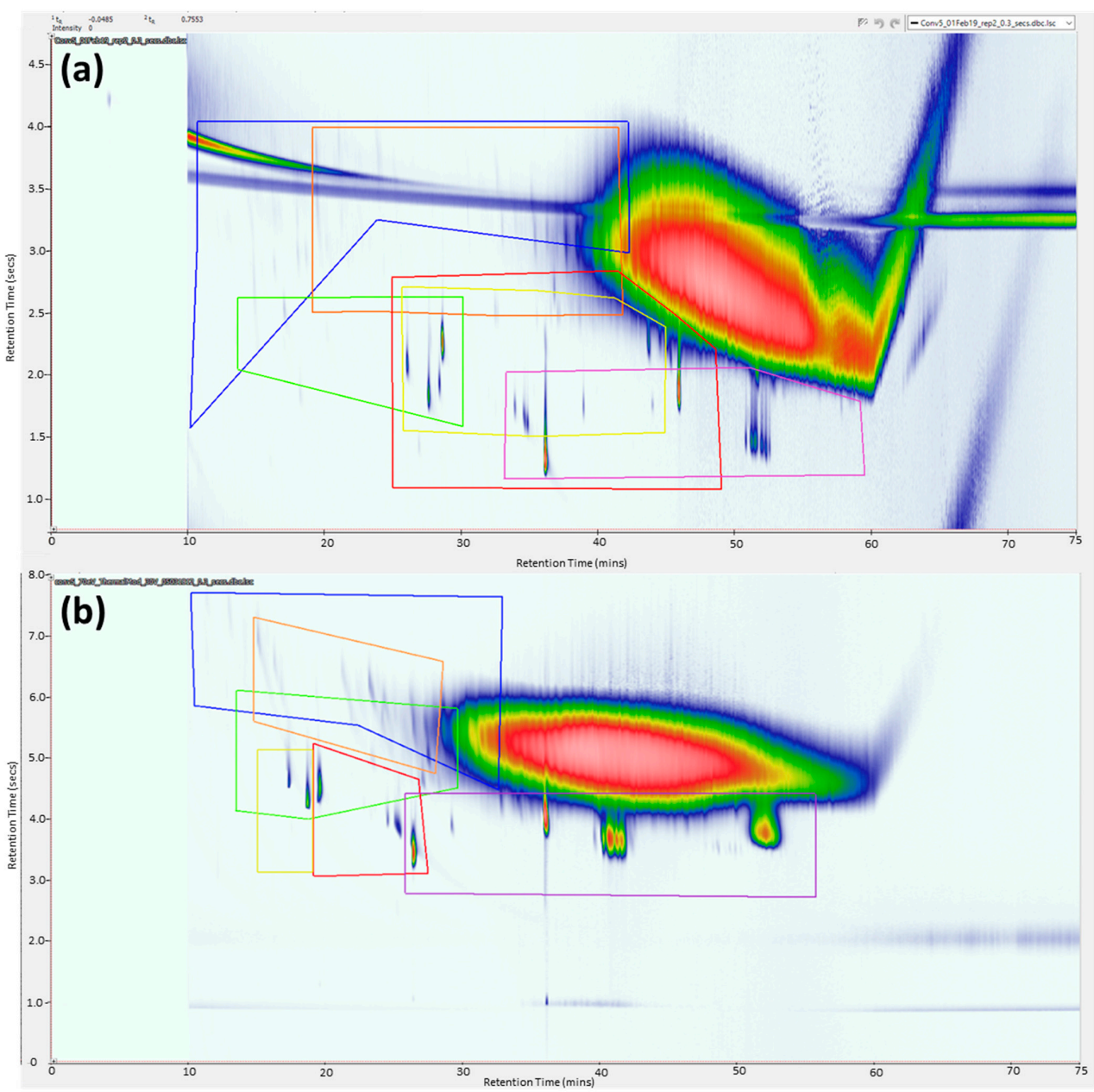

Figure 6. Group analysis of a conventional oil from Brand A with viscosity 5W-20 illustrating the separation with (a) a flow-based modulator platform and (b) a thermal-based modulator platform. The colors presented correspond to the following groups: Blue for paraffins and isoparaffins, green for alkylbenzenes, orange for mononaphthenes, yellow for dinaphthenes, red for trinaphthenes, and purple for naphthalenes.

\subsection{Thermal Modulation vs. Flow Modulation}

Figure 7 illustrates the conventional oil separations for the thermal modulator platform. Each chromatogram displays several homologous groups, a large UCM, and two distinct groups separated from the UCM (indicated with black circles). The main differences were observed in the nature of the alkanes eluting late in the ${ }^{2} \mathrm{D}$, as well as in the distribution of hydrocarbons within the UCM. Specifically, in Figure 7a, the brand A 10W-30 conventional oil contained significantly more straight-chain alkanes when compared to the three other conventional samples (b-d). Brand A 5W-20 conventional oil (Figure 7c) contained a higher concentration of di- and tri-substituted naphthenes when compared to the other conventional samples ( $a, b$, and d). When comparing the distribution of compounds within the UCM of the four conventional samples, it could be seen that each blend was slightly different from the others. Brand A 10W-30, as seen in Figure 7a, had a relatively consistent distribution of hydrocarbons within the UCM. Brand B 10W-30 conventional oil (Figure 7b) had a distribution that extended further toward heavier hydrocarbons. Brand A and B 5W-20 oils contained lower concentrations of high-molecular-weight hydrocarbons, which explains their lower viscosity at low temperatures. A key similarity in all four samples was the presence of two distinct groups (indicated by the black circles) separated from the UCM at about 40 and $50 \mathrm{~min}$. Further investigation of these groups will be discussed in Section 3.4. 
(a)

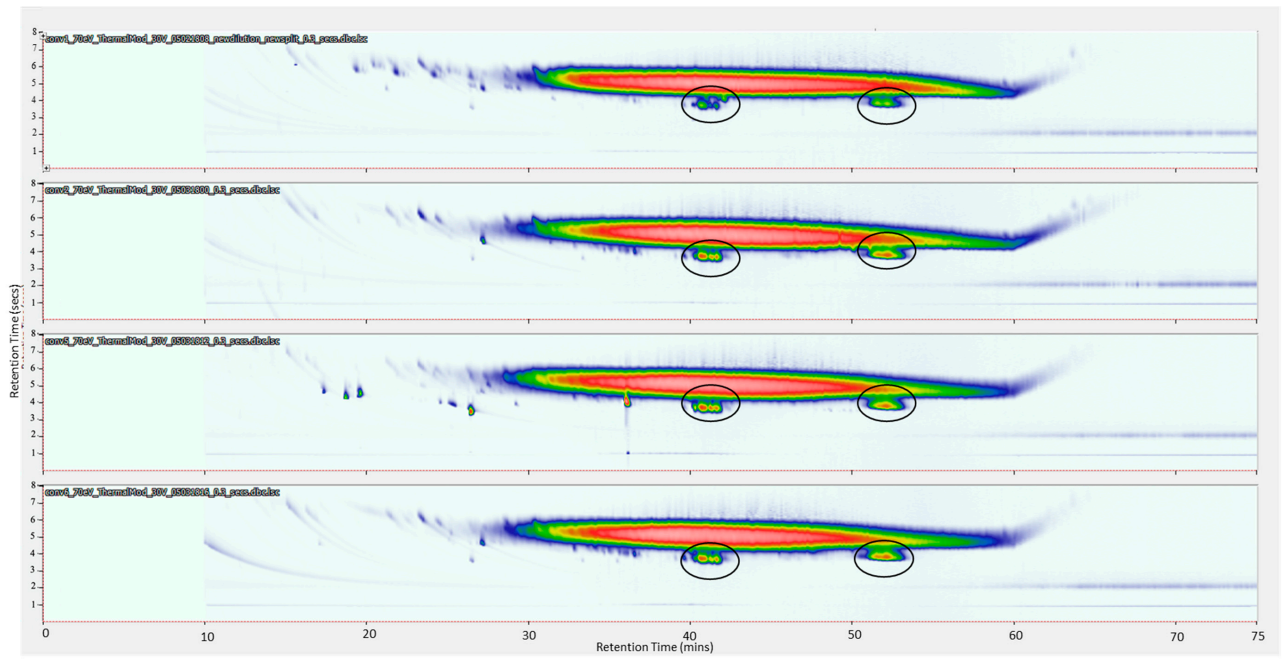

Figure 7. GC $\times$ GC-TOF-MS contour plots of (a) conventional oil from Brand A with viscosity 10W-30; (b) conventional oil from Brand B with viscosity 10W-30; (c) conventional oil from Brand A with viscosity 5W-20; and (d) conventional oil from Brand B with viscosity 5W-20, illustrating the separation with the thermal-based modulator platform.

The conventional oil separations for the flow modulation platform with TOF mass spectrometric detection can be seen in Figure 8. When comparing these chromatograms to those in Figure 7, the differences are obvious. It is important to note that with the thermal modulator platform, the length of the second-dimension column was optimized and a longer modulation period was used to avoid wraparound and excessive retention in the second dimension. Due to the operational constraints of the flow modulator, such as the required lengthy ${ }^{2} \mathrm{D}$ column and short modulation period, a similar optimization was not possible. This resulted in wraparound in the isothermal hold region of the chromatograms. The two distinct groups (indicated by black circles) previously distinguished with the thermal modulator were also separated with the flow modulator. These groups were located at approximately 50 and $65 \mathrm{~min}$. The abundance of the latter group was lower when compared to that obtained with the thermal platform.

(a)

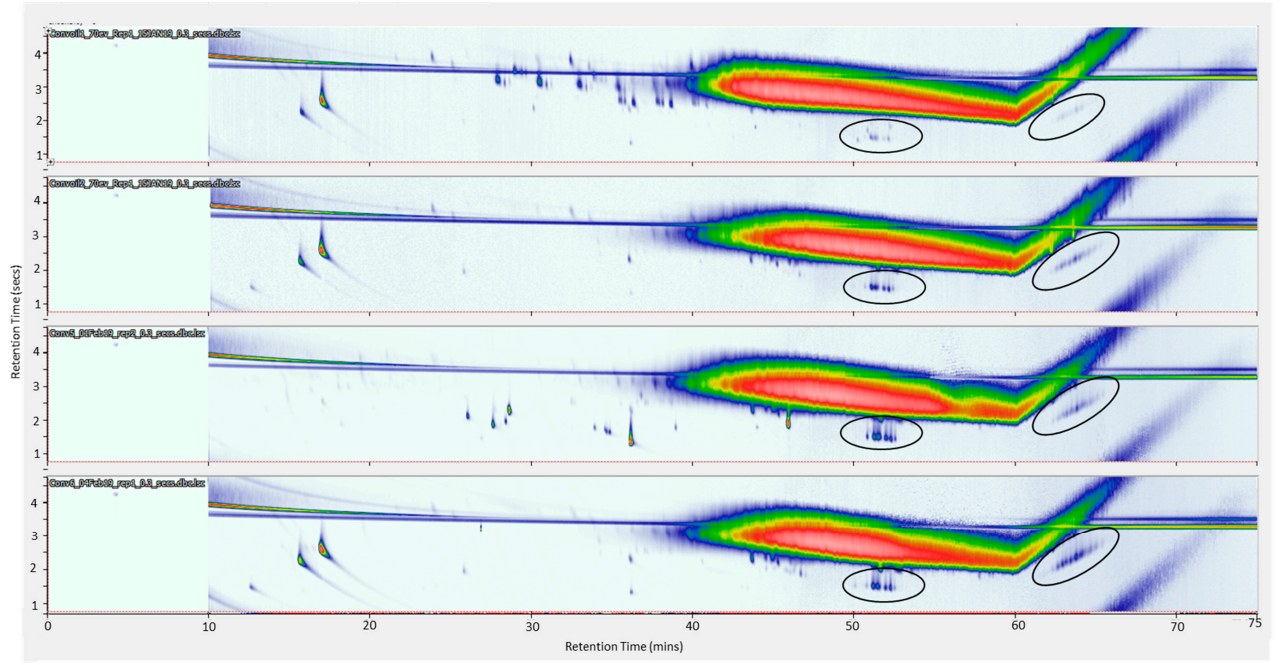

Figure 8. GC $\times$ GC-TOF-MS contour plots of (a) conventional oil from Brand A with viscosity 10W-30; (b) conventional oil from Brand B with viscosity 10W-30; (c) conventional oil from Brand A with viscosity 5W-20; and (d) conventional oil from Brand B with viscosity 5W-20, illustrating the separation with the flow-based modulator platform. 
The distribution of paraffinic compounds within Brand A 10W-30, as seen in Figure 8a, was found to be very similar when utilizing the flow modulator platform. The di- and tri-substituted naphthenes in Brand A 5W-20 oil were also apparent when utilizing the flow modulator platform, as seen in Figure 8c. Brand A 10W-30 conventional oil, as seen in Figure 8a, had a large presence of lower-molecular-weight hydrocarbons that eluted before the UCM when compared to the other conventional samples. Figure $8 \mathrm{~b}$, Brand B 10W-30 conventional oil, had an even distribution of hydrocarbons in the UCM. Figure 8d, Brand B 5W-20 conventional oil, had a smaller region of middle-weight-molecular-range hydrocarbons when compared to the $10 \mathrm{~W}-30$ variety from the same brand. The ${ }^{1} \mathrm{D}$ and ${ }^{2} \mathrm{D}$ retention times of the compounds varied between both platforms due to differences in the ${ }^{1} \mathrm{D}$ and ${ }^{2} \mathrm{D}$ flow rates and ${ }^{2} \mathrm{D}$ column dimensions.

The synthetic oil chromatograms obtained with the thermal modulator differed from one another, as seen in Figure 9. The distribution of hydrocarbons within the UCM clearly differentiated each synthetic oil. In Brand A 10W-30 oil (Figure 9a), the distribution was relatively uniform throughout, from the lighter- to heavier-molecular-weight hydrocarbons. However, the UCM of Brand B 10W-20 oil (Figure 9b) was very different. The heavier hydrocarbons spanned a larger range than in the other oils. The distribution of the hydrocarbons was also more uniform, with the widest range of hydrocarbons overall. The distribution peaked roughly in the middle of the UCM. Figure 9c displays the chromatogram of Brand A 5W-20 synthetic oil, with a large concentration of middle-weight hydrocarbons, and more lighter hydrocarbons than heavier. Finally, Brand B 5W-20 (Figure 9d) also contained a high concentration of middle-weight hydrocarbons, with lower concentrations of heavy and light compounds. On the other hand, the distribution of analytes before the UCM was similar between brands. As seen in Figure $9 a, c$, there was a higher concentration of di- and tri-substituted naphthenes and a trace number of paraffinic compounds for Brand A, while Brand B (Figure 9b,d) contained a higher concentration of paraffinic compounds, as well as a third group that was differentiated from the UCM. The two distinct groups (indicated with black circles) that were present within the conventional samples were also present within the synthetic samples with the same corresponding ${ }^{1} \mathrm{D}$ retention times of approximately 40 and $50 \mathrm{~min}$.

(a)

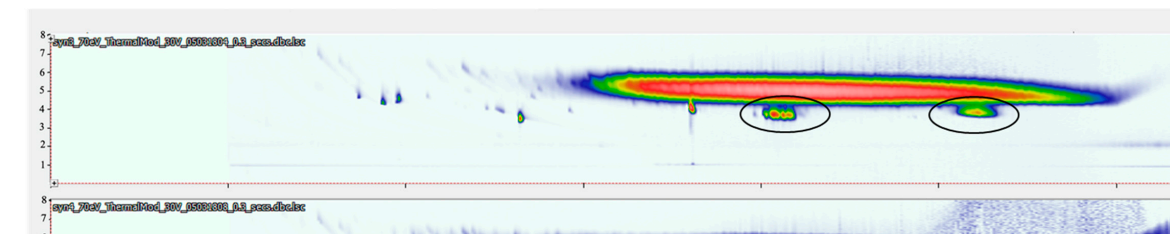

(b)

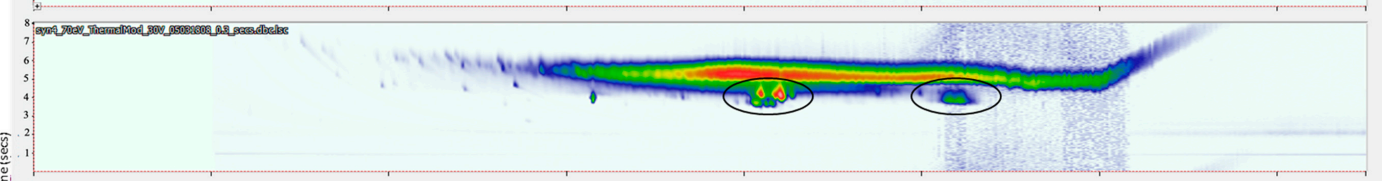

(c)

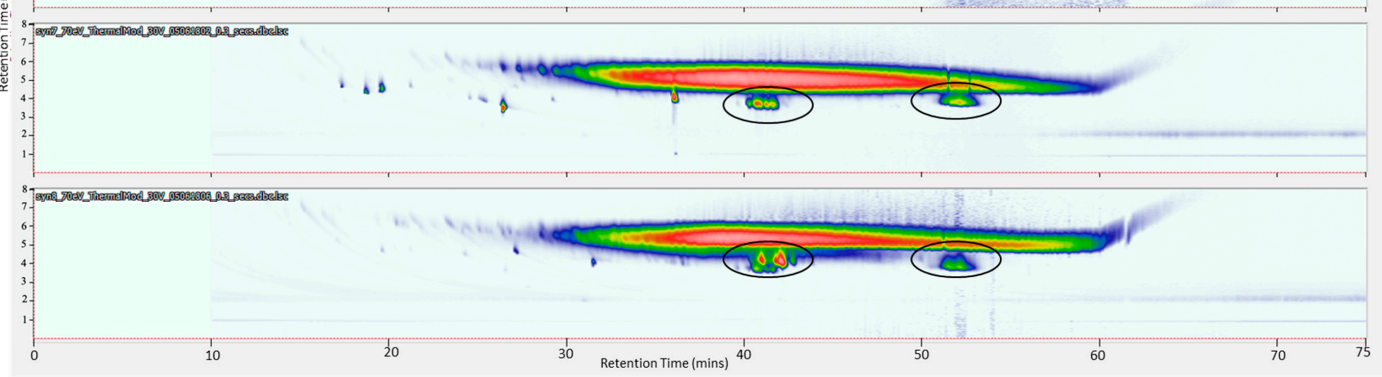

Figure 9. GC $\times$ GC-TOF-MS contour plots of (a) synthetic oil from Brand A with viscosity 10W-30; (b) synthetic oil from Brand B with viscosity 10W-30; (c) synthetic oil from Brand A with viscosity $5 \mathrm{~W}-20$; and (d) synthetic oil from Brand B with viscosity 5W-20, illustrating the separation with the thermal-based modulator platform.

As previously seen in the synthetic oil chromatograms obtained with the thermal modulator platform, similarities were observed in the distribution of the di- and tri-substituted naphthenes for 
the different viscosities of Brand A analyzed with the flow platform (Figure 10a,c). The observed distribution of the hydrocarbons within the UCM was also quite distinct for each sample analyzed using flow modulation. It mirrored the results obtained with the thermal platform. The two distinct groups (as indicated with black circles) were present in each of the four synthetic samples when utilizing the flow-based modulator platform. The second group, however, was again less prominent when compared to the thermal modulator platform. On the other hand, two new groups separated from the UCM (indicated by black squares) were observed with the flow-based platform for Brand B oils that have not been previously separated, as seen in Figure 10b,d, respectively.

(a)

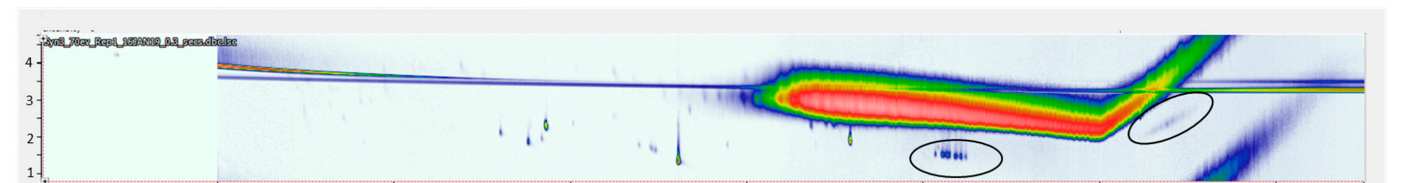

(b)

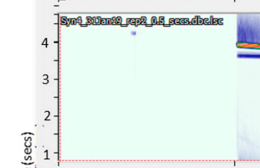

(c)

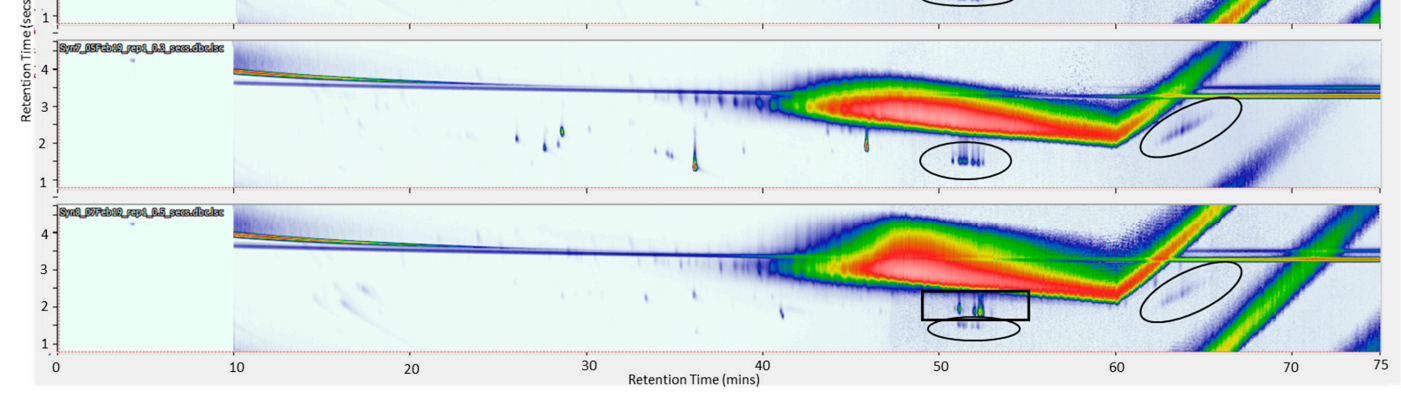

Figure 10. GC $\times$ GC-TOF-MS contour plots of (a) synthetic oil from Brand A with viscosity 10W-30; (b) synthetic oil from Brand B with viscosity 10W-30; (c) synthetic oil from Brand A with viscosity $5 \mathrm{~W}-20$; and (d) synthetic oil from Brand B with viscosity 5W-20, illustrating the separation with the flow-based modulator platform.

\subsection{Identification of Antioxidants through Soft Ionization}

Preventing oxidation of lubricants within the operational machinery is a vital part of ensuring no harmful species are generated, eventually compromising the life and functionality of the lubricant. An antioxidant additive is a key component in protecting the lubricant from oxidation, allowing the oil to perform optimally [33]. Alkylated diphenylamines (ADPAs) have been used for this purpose for over two decades, providing higher reactivity than unsubstituted diphenylamine [33]. Mono-ADPA are more effective than di-ADPA due to the additional alkylation decreasing the amount of diphenylamine per unit weight [33]. Identification of ADPAs is an important part of engine oil characterization. Due to their aromatic nature, they should appear lower in the two-dimensional space with shorter ${ }^{2} \mathrm{D}$ retention times due to their strong retention in the ${ }^{1} \mathrm{D}$ column and subsequently higher ${ }^{1} \mathrm{D}$ elution temperature. Diphenylamine was tentatively identified in each sample with both thermal and flow modulation by comparing the experimental spectrum with the NIST library spectrum, as seen in Figure 11a,b, respectively. However, identification of the components of the two prominent groups separated from the UCM within each sample proved more problematic, as the agreement between library hits and experimental spectra was poor. The molecular ion in each case was barely visible, making identification difficult. 


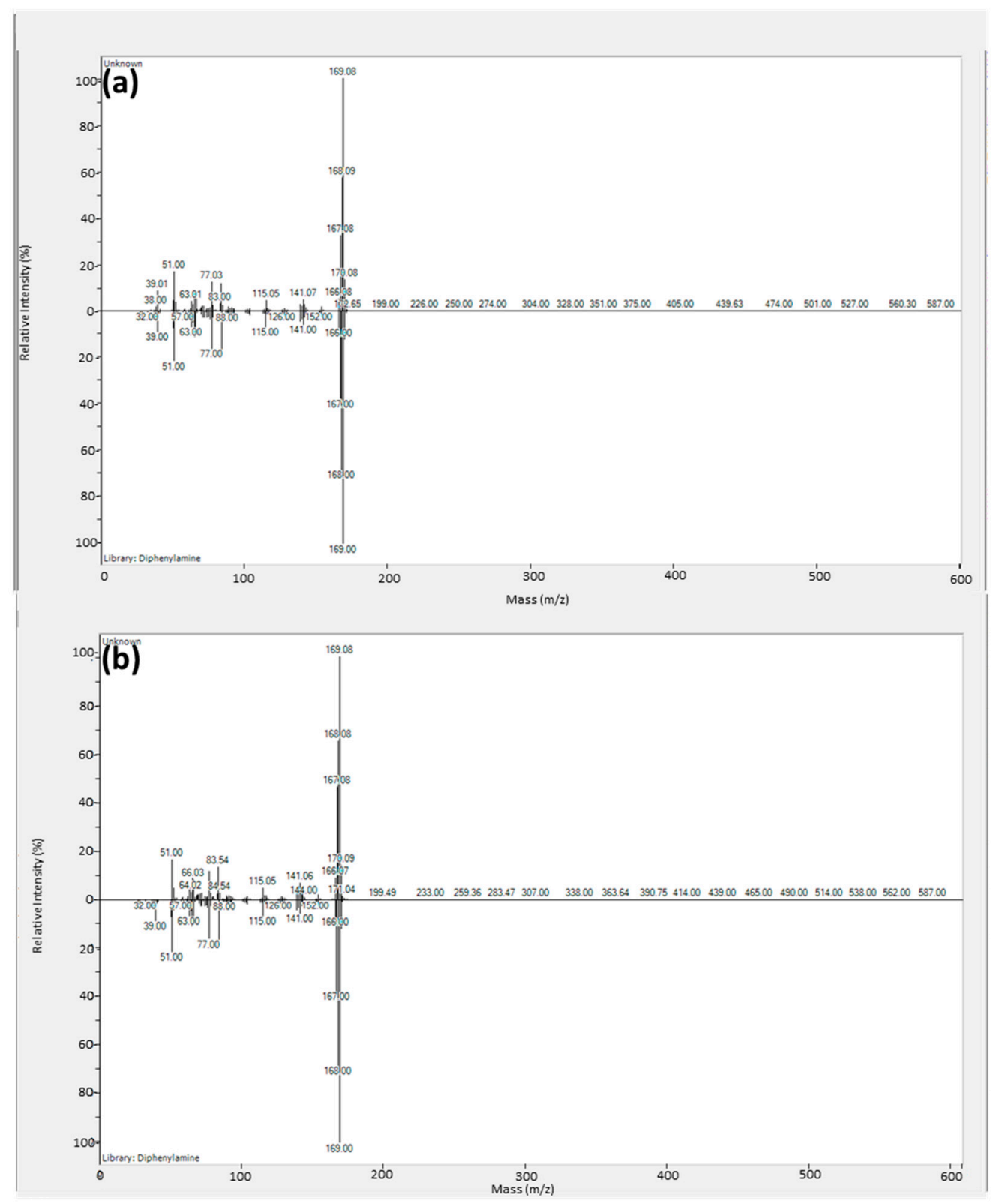

Figure 11. GC $\times$ GC-TOF-MS mass spectra of (a) diphenylamine with the flow-based platform and (b) diphenylamine with the thermal-based platform.

To overcome these limitations, soft ionization was implemented to reduce fragmentation and increase the abundance of the molecular ion. Figure 12a-d compare the mass spectra obtained for the two distinct groups separated from the UCM at 14 and $70 \mathrm{eV}$. The groups were previously noted at ${ }^{1} \mathrm{D}$ retention times of 40 and $50 \mathrm{~min}$ with the thermal modulator and 50 and $65 \mathrm{~min}$ with the flow modulator. It is apparent that the soft ionization technique created more prominent molecular ions while reducing overall fragmentation and increasing the abundance of higher-mass fragments to assist in the identification process. The poor agreement between the experimental and library spectra for the unknowns suggested that the latter were not included in the NIST library. The only available ADPA spectrum within the NIST library is the dioctyl substituted diphenylamine. As seen in Figure S1 of Supporting Information, the mass spectrum of the dioctyl-substituted diphenylamine displayed the molecular ion of $393 \mathrm{~m} / \mathrm{z}$ with two $\mathrm{C}_{8} \mathrm{H}_{17}$ alkyl substitutions off the diphenylamine backbone. Despite there being no exact match within the NIST library for the unknown species eluting from the 
UCM, the soft ionization technique enhanced the molecular ions, which were used for comparison to the known mass of the dioctyl ADPA. The first unknown displayed a molecular ion of $296 \mathrm{~m} / \mathrm{z}$, located at ${ }^{1} \mathrm{D}$ retention times of about 50 and $40 \mathrm{~min}$ for the flow modulator and thermal modulator, respectively. Based on this information, a preliminary identification of monononyl diphenylamine was made.

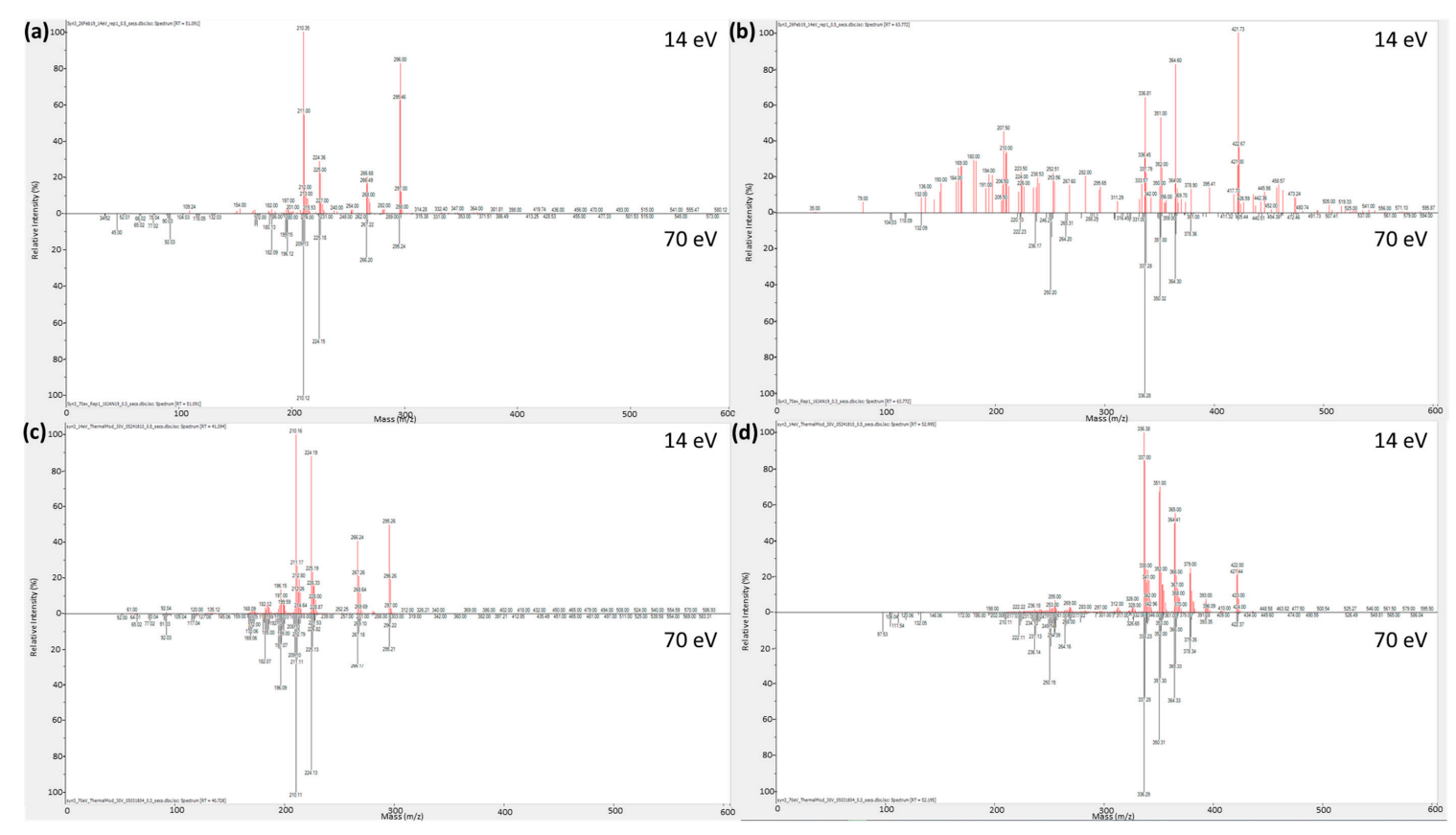

Figure 12. GC $\times$ GC-TOF-MS mass spectra comparison using hard and soft ionization for the identification of (a) monononyl-diphenylamine with the flow-based platform; (b) dinonyl-diphenylamine with the flow-based platform; (c) monononyl-diphenylamine with the thermal-based platform; and (d) dinonyl-diphenylamine with the thermal-based platform.

The second unknown displayed a molecular ion of $422 \mathrm{~m} / \mathrm{z}$, located at ${ }^{1} \mathrm{D}$ retention times of about 65 and $50 \mathrm{~min}$ for the flow modulator and thermal modulator, respectively. Based on this information, a preliminary identification of dinonyl diphenylamine was made. It is important to note the differences in the spectra obtained for dinonyl diphenylamine with the flow modulator (Figure 12b) and thermal modulator (Figure 12d). The quality of the spectrum obtained with the flow modulator was lower due to the lower abundance of the peak. The larger-mass fragments obtained with soft ionization assisted in further confirming the tentative identification of these unknowns through a comparison with mass spectral data obtained for known standards by Lu et al. [34]. In this paper, substituted diphenylamine antioxidants were identified within urban creeks of Canada utilizing tandem mass spectrometry [34]. Table S1 in Supporting Information displays the multiple reactions monitoring diagnostic transitions used by Lu et al., which were subsequently used for comparison with the soft ionization mass spectral data and tentative identification of the unknown ADPAs present within the oils. Nonetheless, analysis of authentic standards is required for positive identification of both the monononyl and dinonyl diphenylamines.

\subsection{Resolution from UCM}

Determining the resolution of the identified ADPA species from the UCM helps compare the separation capabilities of both modulator platforms. Differentiating the ADPA species from the UCM allows confident identification thanks to clean mass spectra. For this application, the calculations of the resolution from UCM were performed for the FID trace to avoid the issues encountered with ion source tailing. The flow modulator platform provided a better overall resolution for monononyl DPA 
from the UCM when compared to the thermal modulator, as seen in Table 2. This was most likely due to the longer ${ }^{2} \mathrm{D}$ column used. When directly compared to the thermal modulator, the flow modulator provided better resolution for synthetic samples 3 and 7 and conventional samples 2, 5, and 6 . It should be noted that the resolution values listed for synthetic samples 4 and 8 for the flow modulator were not the resolution values from the UCM. They were instead the resolution from a new set of compounds eluting from the UCM that the thermal modulator platform could not separate. When comparing the resolution for the dinonyl DPA for the flow and thermal platforms, it was difficult to determine the values due to the low abundance of this compound in the FID trace.

Table 2. Resolution from the unresolved complex mixture (UCM) for monononyl DPA for both the flow-based and thermal-based platforms.

\begin{tabular}{cccc}
\hline Sample & Compound & Flow Modulator & Thermal Modulator \\
\hline Conventional 1 & Monononyl DPA & 0.91 & 1.3 \\
Conventional 2 & Monononyl DPA & 1.8 & 1.5 \\
Synthetic 3 & Monononyl DPA & 3.3 & 1.4 \\
Synthetic 4 & Monononyl DPA & 0.99 & 1.2 \\
Conventional 5 & Monononyl DPA & 2.1 & 1.7 \\
Conventional 6 & Monononyl DPA & 2.0 & 1.7 \\
Synthetic 7 & Monononyl DPA & 2.0 & 1.6 \\
Synthetic 8 & Monononyl DPA & 1.4 & 1.6 \\
\hline
\end{tabular}

\section{Conclusions}

A reverse fill/flush flow modulator and single-stage, consumable-free thermal modulator were compared for the separation of several conventional and synthetic engine oils of various viscosities and brands with dual detection. The closed design of the select ionization TOF-MS was detrimental in obtaining baseline resolution of the heavier-molecular-weight compounds and UCM, in comparison to the FID. Appropriate data processing was necessary to differentiate and visualize minor components separated from the UCM when using TOF-MS. Overall, both brands of engine oils had similar compositions. Upon closer inspection, differences were found based on the distribution of hydrocarbons within the UCM. When both platforms were optimized according to their operational parameters, the thermal modulator and flow modulator performed comparably in the separation of analytes from the UCM. The thermal platform produced less wraparound of the isothermal portion of the analysis when compared to the flow platform thanks to a longer modulation period that was possible with this platform. The flow modulator platform was more constrained in the optimization process.

Stencils based on characteristic ions and position in the 2D space allowed easy identification of various compound groups within the engine oils. Soft ionization was used to enhance the molecular ion and larger mass fragments to aid in identification of unknown compounds. It proved vital in tentative identifications of monononyl and dinonyl diphenylamines in all samples. Supplementing traditional ionization at $70 \mathrm{eV}$ with soft ionization techniques should be performed more frequently when compounds of similar nature are investigated. Both flow and thermal modulation provided adequate resolution of the monononyl diphenylamine from the UCM. Neither model was superior to the other and a direct comparison between two modulators of different operating principles was not possible. Both flow modulation and thermal modulation achieved comprehensive separation of specific compound classes and allowed the differentiation of engine oils.

Supplementary Materials: The following are available online at http://www.mdpi.com/2297-8739/7/4/70/s1, Figure S1: Mass spectrum of dioctyl-substituted diphenylamine within the NIST library, Table S1: Chemical name, structure and multiple reaction monitoring (MRM) transitions.

Author Contributions: Conceptualization, M.E.; Methodology, H.A.B.; Software, H.A.B. and M.E.; Validation, H.A.B.; Formal Analysis, H.A.B.; Investigation, H.A.B. and T.G.; Resources, T.G.; Data Curation, H.A.B.; Writing-Original Draft Preparation, H.A.B.; Writing-Reviewing \& Editing, H.A.B. and T.G.; Visualization, 
H.A.B.; Supervision, T.G.; Project Administration, T.G.; Funding Acquisition, T.G. All authors have read and agreed to the published version of the manuscript.

Funding: Funding for this research was provided by NSERC.

Acknowledgments: Natural Sciences and Engineering Research Council of Canada (NSERC) is gratefully acknowledged for providing funding for this research.

Conflicts of Interest: The authors declare no competing financial interest.

\section{References}

1. Bello, S.; Bello, K. Production Process of Base Oils: The Prospects and Challenges for Local Industries in Nigeria. Int. J. Eng. Technol. 2016, 36, 452-456.

2. Silva, S.L.; Silva, A.M.; Riberio, J.C.; Martins, F.G.; Da Silva, F.A.; Silva, C.M. Chromatographic and spectroscopic analysis of heavy crude oile mixtures with emphasis in nuclear magnetic resonance spectroscopy: A review. Anal. Chim. Acta 2011, 707, 18-37. [CrossRef] [PubMed]

3. Severa, L.; Havlicek, M.; Kumbar, V. Temperature dependent kinematic viscosity of different types of engine oils. Acta. Univ. Agric. Silvec. 2009, 57, 95-102. [CrossRef]

4. Balabin, R.M.; Safieva, R.Z. Motor oil classification by base stock and viscosity based on near infrared (NIR) spectroscopy data. Fuel 2008, 87, 2745-2752. [CrossRef]

5. Fortunato de Varvalho Rocha, W.; Schantz, M.M.; Sheen, D.A.; Chu, P.M.; Lippa, K.A. Unsupervised classification of pertroleum Certified Reference Materials and other fuels by chemometric analysis of gas chromatography-mass spectrometry data. Fuel 2017, 197, 248-258. [CrossRef]

6. Vendeuvre, C.; Bertoncini, F.; Duval, L.; Duplan, J.-L.; Thiebaut, D.; Hennion, M.-C. Comparison of conventional gas chromatography (1D-GC) and comprehensive two-dimensional gas chromatography (GCxG) for the detailed analysis of petrochemical samples. J. Chromatogr. A 2004, 1056, 155-162. [CrossRef]

7. von Muhlen, C.; Zini, C.A.; Caramao, E.B.; Marriott, P.J. Applications of comprehensive two-dimensional gas chromatography to the characterization of petrochemical and related samples. J. Chromatogr. A 2006, 1105, 39-50. [CrossRef]

8. Da Costa, C.; Turner, M.; Reynolds, J.C.; Whitmarsh, S.; Lynch, T.; Creaser, C.S. Direct analysis of oil additives by high-field asymmetric waveform ion mobility spectrometry-mass spectrometry combined with electrospray ionization and desorption electrospray ionization. Anal. Chem. 2016, 88, 2453-2458. [CrossRef]

9. Kreisberger, G.; Klampfl, C.W.; Buchberger, W.W. Determination of antioxidants and corresponding degradation products in fresh and used engine oils. Energy Fuels 2016, 30, 7638-7645. [CrossRef]

10. Djokic, M.R.; Dijmans, T.; Yildiz, G.; Prins, W.; Van Geem, K.M. Quantitative anlaysis of crude and stabilized bio-oils by comprehensive two-dimensional gas-chromatography. J. Chromatogr. A 2012, 1257, 131-140. [CrossRef]

11. Jennerwein, M.K.; Sutherland, A.C.; Eschner, M.; Groger, T.; Wilharm, T.; Zimmermann, R. Quantitative analysis of modern fuels derived from middle distillates-The impact of diverse compositions on standard methods evaluated by an offline hyphenation of HPLC-refractive index detection with GCxGC-TOFMS. Fuel 2017, 187, 16-25. [CrossRef]

12. Gallacher, C.; Thomas, R.; Taylor, C.; Lord, R.; Kalin, R.M. Comprehensive composition of Creosote using comprehensive two-dimensional gas chromatography time-of-flight mass spectrometry (GCxGC-TOFMS). Chemosphere 2017, 178, 34-41. [CrossRef] [PubMed]

13. Lorentz, C.; Laurenti, D.; Zotin, J.L.; Geantet, C. Comprehensive GC x GC chromatography for the characterization of sulfur compound in fuels: A review. Catal. Today 2017, 292, 26-37. [CrossRef]

14. Nizio, K.D.; McGinitie, T.M.; Harynuk, J.J. Comprehensive multidimensional separations for the analysis of petroleum. J. Chromatogr. A 2012, 1255, 12-23. [CrossRef]

15. Webster, R.L.; Rawson, P.W.; Kulsing, C.; Evans, D.J.; Marriott, P.J. Investigation of the thermal oxidation of conventional and alternate aviation fuels with comprehensive two-dimensional gas chromatography accurate mass quadrupole time-of-flight mass spectrometry. Energy Fuels 2017, 31, 4886-4894. [CrossRef]

16. Tran, T.C.; Logan, G.A.; Grosjean, E.; Harynuk, J.; Ryan, D.; Marriott, P. Comparison of column phase configurations for comprehensive two-dimensional gas chromatographic analysis of crude oil and bitumen. Org. Geochem. 2006, 37, 1190-1194. [CrossRef] 
17. Murphy, R.E.; Schure, M.R.; Foley, J.P. Effect of sampling rate on resolution in comprehensive two-dimensional liquid chromatography. Anal. Chem. 1998, 70, 1585-1594. [CrossRef]

18. Gorecki, T.; Harynuk, J.; Panic, O. The evolution of comprehensive two-dimensional gas chromatography (GCxGC). J. Sep. Sci. 2004, 27, 359-379. [CrossRef]

19. Edwards, M.; Mostafa, A.; Gorecki, T. Modulation in comprehensive two-dimensional gas chromatography: 20 years of innovation. Anal. Bioanal. Chem. 2011, 401, 2335-2349. [CrossRef]

20. Gorecki, T.; Panic, O.; Oldridge, N. Recent advances in comprehensive two-dimensional gas chromatography (GCxGC). J. Liq. Chromatogr. Relat. 2006, 29, 1077-1104. [CrossRef]

21. Adahchour, M.; Beens, J.; Vreuls, R.J.; Brinkman, U.T. Recent developments in comprehensive two-dimensional gas chromatography (GCxGC) II. Modulation and detection. Trends Anal. Chem. 2006, 25, 540-553. [CrossRef]

22. Prebihalo, S.E.; Berrier, K.L.; Freye, C.E.; Bahaghighat, N.R.; Moore, N.R.; Pinkerton, D.K.; Synovec, R.E. Multidimensional gas chromatography: Advance in instrumentation, chemometrics and applications. Anal. Chem. 2018, 90, 505-532. [CrossRef] [PubMed]

23. Bahaghighat, H.D.; Freye, C.E.; Synovec, R.E. Recent advances in modulator technology for comprehensive two-dimensional gas chromatography. Trends Anal. Chem. 2018, 113, 1-13. [CrossRef]

24. Duhamel, C.; Cardinael, P.; Peulon-Agasse, V.; Firor, R.; Pascaud, L.; Semard-Jousset, G.; Giusti, P.; Livadaris, V. Comparison of cryogenic and differential flow (forward and reverse fill/flush) modulators and applications to the anlaysis of heavy petroleum cuts by high-temperature comprehensive gas chromatography. J. Chromatogr. A 2015, 1387, 95-103. [CrossRef] [PubMed]

25. Semard, G.; Couin, C.; Bourdet, J.; Bord, N.; Livadaris, V. Comparative study of differential flow and cryogenic modulators comprehensive two-dimensional gas chromatography systems for the detailed analysis of light cycle oil. J. Chromatogr. A 2011, 1218, 3146-3152. [CrossRef] [PubMed]

26. Alam, M.S.; Stark, C.; Harrison, R.M. Using variable ionization energy time-of-flight mass spectrometry with comprehensive GCxGC to identify isomeric species. Anal. Chem. 2016, 88, 4211-4220. [CrossRef] [PubMed]

27. Markes International Ltd. Select-eV: The Next Generation of Ion Source Technology (Application Note 528); Markes International Ltd.: Llantrisant, UK, 2016; pp. 1-8.

28. Muscalu, A.; Edwards, M.; Gorecki, T.; Reiner, E. Evaluation of a single-stage consumable-free modulator for comprehensive two-dimensional gas chromatography: Analysis of polychlorinated biphenyls, organochlorine pesticides and chlorobenzenes. J. Chromatogr. A 2015, 1391, 93-101. [CrossRef] [PubMed]

29. SepSolve Analytical Ltd. Insight Flow Modulator User Guide; SepSolve Analytical Ltd.: Peterborough, UK, 2016; pp. 1-9.

30. Striebach, R.C.; Shafer, L.M.; Adams, R.K.; West, Z.J.; DeWitt, M.J.; Zabarnick, S. Hydrocarbon group-type analysis of petroleum-derived and synthetic fuels using two-dimensional gas chromatography. Energy Fuels 2014, 28, 5696-5706. [CrossRef]

31. Jennerwein, M.K.; Eschner, M.; Groger, T.; Wilharm, T.; Zimmermann, R. Complete group-type quantification of petroleum middle distillates based on comprehensive two-dimensional gas chromatography time-of-flight mass spectrometry (GCxGC-TOFMS) and visual basic scripting. Energy Fuels 2014, 28, 5670-5681. [CrossRef]

32. Lissitsyna, K.; Huertas, S.; Quintero, L.; Polo, L. PIONA analysis of kerosene by comprehensive two-dimensional gas chromatography coupled to time of flight mass spectrometry. Fuel 2014, 116, 716-722. [CrossRef]

33. Rudnick, L.R. Lubricant Additives: Chemistry and Applications; Taylor \& Francis Group: Boca Raton, FL, USA, 2009.

34. Lu, Z.; De Silva, A.O.; Peart, T.E.; Cook, C.J.; Tetreault, G.R.; Servos, M.R.; Muir, D.C. Distribution, partitioning and bioaccumulation of substituted diphenylamine antioxidants and benzotriazole UV stabilizers in an urban creek in Canada. Environ. Sci. Technol. 2016, 50, 9089-9097. [CrossRef] [PubMed]

Publisher's Note: MDPI stays neutral with regard to jurisdictional claims in published maps and institutional affiliations. 